\title{
INKONSISTENSI KEBIJAKAN ENERGI DI INDONESIA: KAITANNYA TERHADAP PEMBERLAKUAN STANDAR EMISI GAS BUANG EURO 4
}

\author{
Agus Efendi ${ }^{1}$, Alia Yofira Karunian ${ }^{2}$, Ni Luh Putu Chintya Arsani ${ }^{3}$
}

\begin{abstract}
Abstrak
Disahkannya Perpres No. 191 Tahun 2014 tentang Penyediaan, Pendistribusian dan Harga Jual Eceran Bahan Bakar Minyak pada 31 Desember 2014 lalu menandakan komitmen Indonesia dalam mengurangi penggunaan energi tak ramah lingkungan. Perpres No. 191 Tahun 2014 ini membatasi pendistribusian Premium untuk wilayah yang menghasilkan gas buang kendaraan bermotor dengan jumlah besar seperti Jawa dan Bali. Namun, pada 24 Mei 2018 lalu, Presiden Jokowi mengesahkan Perpres No. 43 Tahun 2018 yang kembali mewajibkan pendistribusian Premium di wilayah Jawa dan Bali. Rencana ini bertentangan dengan komitmen Indonesia dalam mengimplementasikan baku mutu emisi gas buang Euro 4 yang diadopsi melalui Permen LH No. 20 Tahun 2017 tentang Baku Mutu Emisi Gas Buang Kendaraan Bermotor Tipe Baru Kategori M, N, dan O. Artikel ini mengaplikasikan metode penelitian audit kebijakan. Simpulan dari artikel ini adalah evidence-based policy making tidak diimplementasikan dalam perumusan Perpres No. 43 Tahun 2018. Meskipun bukti ilmiah menunjukkan bahwa Premium tidak memenuhi standar Euro 4, Pemerintah tetap bersikeras mewajibkan kembali pendistribusian Premium di wilayah Jawa dan Bali.
\end{abstract}

Kata kunci: Evidence-based policy making, Premium, Euro 4

\section{Abstract}

The enactment of Presidential Regulation No. 191 Year 2014 concerning Provision, Distribution and Retail Price of Fuel Oil on December 31 2014 signified Indonesia's commitment in reducing the use of not environmentally friendly energy. This regulation limits Premium distribution to areas that produce large amounts of motor vehicle exhaust e.g. Java and Bali. However, on 24th May 2018, President Jokowi promulgated Presidential Regulation No. 43 Year 2018 which will again require Premium distribution in Java and Bali. This plan is contrary to Indonesia's commitment to implement the Euro 4 emission quality standard adopted through Ministerial Regulation No. 20 of 2017 concerning the Exhaust Emission Standards of New Type Motor Vehicle with M, N, O Category. This article applies policy-audit research methodology. This article's conclusion is, the evidence-based policy making is not

${ }^{1}$ Penulis adalah lulusan Fakultas Hukum Universitas Udayana dengan program kekhususan Hukum Internasional.

${ }^{2}$ Penulis adalah lulusan Fakultas Hukum Universitas Udayana dan saat ini bekerja sebagai Peneliti Muda di Lembaga Studi dan Advokasi Masyarakat (ELSAM).

3 Penulis adalah Mahasiswa Program Sarjana Fakultas Hukum Universitas Udayana. 
implemented in the promulgation of Presidential Regulation No. 43 Year 2018. Although the scientific evidence shows that Premium does not meet Euro 4 standards, the Government still insists to again require the Premium distribution in Java and Bali.

Keywords: Evidence-based policy making, Premium, Euro 4

\section{Pendahuluan}

Secara global, dalam rentang waktu 1990 hingga 2015, tingkat kematian yang disebabkan oleh polusi udara meningkat sejumlah $20 \%$ dari 3,5 juta orang menjadi 4,2 juta orang. ${ }^{4}$ Mengontrol emisi gas buang kendaraan bermotor adalah hal yang sangat penting untuk dilakukan demi mengurangi polusi udara. ${ }^{5}$ Upaya untuk mengontrol emisi gas buang kendaraan bermotor dimulai sejak tahun 1990 saat Uni Eropa mengeluarkan peraturan yang mewajibkan penggunaan katalis untuk mobil bensin yang disebut standar Euro 1. Hal ini bertujuan untuk memperkecil kadar bahan pencemar yang dihasilkan kendaraan bermotor. Selanjutnya secara bertahap Uni Eropa memperketat peraturan menjadi standar Euro 2 (1996), Euro 3 (2000), Euro 4 (2005), Euro 5 (2009), dan Euro 6 (2014). Indonesia juga mulai memberlakukan standar emisi gas buang Euro 4 dengan berbagai pertimbangan.

Standar emisi gas buang Euro 4 pada bahan bakar minyak adalah emisi gas buang yang memiliki kadar gas $\mathrm{CO}$ maksimal $1 \mathrm{gr} / \mathrm{km}, \mathrm{HC}$ 0,1 gr/km, $\mathrm{NO}_{x}$ 0,08 $\mathrm{gr} / \mathrm{km}$ dan untuk mesin diesel memiliki kadar gas maksimal CO 0,50 $\mathrm{gr} / \mathrm{km}, \mathrm{HC}+\mathrm{NO}_{x}$ 0,3 gr/km, pm 0,025 gr/km. ${ }^{6}$ Untuk mengetahui apakah suatu bahan bakar minyak dapat memenuhi standar baku mutu emisi gas buang Euro 4, dapat dilihat dari bilangan oktan bahan bakar tersebut. Bilangan oktan digunakan sebagai istilah untuk menyatakan mutu bensin sebagai bahan

\footnotetext{
${ }^{4}$ Cohen AJ, Brauer M, Burnett R, et al., "Estimates and 25-year Trends of the Global Burden of Disease Attributable to Ambient Air Pollution: An Analysis of Data from the Global Burden of Diseases Study 2015," The Lancet, 389 (2017), hlm. 1907.

${ }^{5}$ Helotonio Carvalho, "The Global Burden of Air Pollution-Associated Deaths - How Many Are Needed for Countries to React?", Elsevier Vol.1, (2017), hlm.179.

6 Anton Suhartono, "Akan Diberlakukan pada 2018, Apa Itu Standar Emisi Euro4?", https://news.okezone.com/read/2017/04/03/15/1657747/akan-diberlakukan-pada-2018-apa-itustan dar-emisi-euro4, diakses pada 7 September 2018
} 
bakar berkompresi tinggi. Semakin tinggi bilangan oktan, maka semakin baik mutu bahan bakar tersebut, ${ }^{7}$ semakin sedikit emisi gas karbon dioksida yang dihasilkan, ${ }^{8}$ dan semakin lambat bahan bakar tersebut terbakar. Hal ini membuat residu yang tertinggal pada mesin sangat sedikit atau bahkan tidak ada sehingga tidak ada gangguan pada kinerja mesin. ${ }^{9}$

Kategori bahan bakar yang memenuhi standar emisi gas buang Euro 4 adalah bahan bakar bernilai oktan minimal $92^{10}$ e.g., Pertamax dengan bilangan oktan 92, Pertamax Plus dengan bilangan oktan 95 dan Pertamax Turbo dengan bilangan oktan 98.11 Karenanya, bahan bakar seperti Premium dengan bilangan oktan 88 dan Pertalite dengan bilangan oktan $90^{12}$ tidak memenuhi standar emisi gas buang Euro 4.13 Premium sendiri sudah tidak beredar di pasar dunia karena tidak memenuhi standar emisi gas buang internasional, selain karena bilangan oktan yang terlalu rendah yaitu 88, kini standar emisi gas buang internasional sudah meningkat menjadi Euro $6 .{ }^{14}$

Pemberlakuan standar emisi gas buang ini bukan tanpa alasan. Perubahan iklim global yang diakibatkan oleh peningkatan aktivitas manusia (antropogenik) yang berimbas pada peningkatan gas rumah kaca, menjadi alasan utama diberlakukannya

${ }^{7}$ Romany M. Webb, Increasing Gasoline Octane Levels to Reduce Vehicle Emissions: A Review of Federal and State Authority (New York: Sabin Center for Climate Change Law, 2017), hlm. 20.

${ }^{8}$ Tim Theiss, et.al., Summary of High-Octane, Mid-Level Ethanol Blends Study 2, (Oak Ridge: Oak Ridge National Laboratory, 2016), hlm. 2.

${ }^{9}$ Ibid.

${ }^{10}$ Kementerian Lingkungan Hidup dan Kehutanan, "Standar Emisi Euro 4 Segera Diberlakukan Di Indonesia”, http://ppid.menlhk.go.id/siaran_pers/browse/579, diakses pada 3 September 2018.

11Praga Utama, "Ini Beda Premium, Pertalite, Pertamax, dan Pertamax Plus", https://bisnis.tempo.co/read/678224/ini-beda-premium-pertalite-pertamax-dan-pertamaxplus/full\&view=ok, diakses pada 3 September 2018.

12 Ibid.

${ }^{13}$ Indonesia, Menteri Lingkungan Hidup dan Kehutanan, Peraturan Menteri Lingkungan Hidup dan Kehutanan tentang Baku Mutu Emisi Gas Buang Kendaraan Bermotor Tipe Baru Kategori M, Kategori N, dan Kategori O, Nomor PM 20 Tahun 2017, Lampiran I (C).

14 Arief Hermawan, "Indonesia Masih Terbelakang Soal Standar Emisi Kendaraan", https://tirto.id/ indonesia-masih-terbelakang-soal-standar-emisi-kendaraan-cjxI, diakses pada 3 September 2018. 
standar emisi gas buang. ${ }^{15}$ Emisi gas antropogenik yang lazim ditemukan di seluruh dunia (baik sebagai polusi udara perkotaan dan deposisi atmosfer lintas batas) adalah, sulfur oksida $\left(\mathrm{SO}_{\mathrm{x}}\right)$, nitrogen oksida $\left(\mathrm{NO}_{\mathrm{x}}\right)$, karbon monoksida $(\mathrm{CO})$, ozon $\left(\mathrm{O}_{3}\right)$, jejak organik (aldehida, benzena dan hidrokarbon plyaromatic), beberapa jenis jejak logam (terutama timbal $(\mathrm{Pb})$ ) dan partikulat tersuspensi, serta polusi udara dari kapal. ${ }^{16}$ Pembakaran bahan bakar fosil, khususnya dari kendaraan bermotor, menghasilkan 2 (dua) nitrogen oksida; nitrogen oksida (NO dan nitrogen dioksida $\left(\mathrm{NO}_{2}\right)$, yang secara kolektif dikenal sebagai $\left.\mathrm{NO}_{\mathrm{x}}\right){ }^{17}$ yang kemudian turut berkontribusi dalam peningkatan antropogenik dari gas rumah kaca dan pada akhirnya akan mengakibatkan pemanasan global dan kerusakan lingkungan.
Sebagai upaya untuk menyesuaikan diri dengan standar emisi gas buang internasional, Presiden Jokowi kemudian membentuk Tim Reformasi Tata Kelola Minyak dan Gas Bumi pada tahun 2014. Beberapa rekomendasi yang diberikan oleh Tim Reformasi Tata Kelola Minyak dan Gas Bumi adalah menyarankan penghentian impor bahan bakar beroktan 88 (Premium) atau bahan bakar lainnya yang beroktan rendah dan menggantinya dengan Pertamax yang beroktan $92^{18}$ serta pengalihan produksi kilang domestik dari bensin beroktan 88 menjadi beroktan 92.19

Rekomendasi ini juga didukung oleh munculnya Peraturan Presiden No. 191 Tahun 2014 tentang Penyediaan, Pendistribusian dan Harga Jual Eceran Bahan Bakar Minyak (selanjutnya disebut Perpres No. 191 Tahun 2014). Perpres ini mengatur pengecualian

${ }_{15}$ Patricia Birnie, et.al., International Law $\mathcal{E}$ the Environment, $3^{\text {rd }}$ ed., (UK: Oxford University Press, 2009), hlm. 336.

16 Philippe Sands, Principles of International Environmental Law, $2^{\text {nd }}$ ed., (UK: Cambridge University Press, 2007), hlm. 323.

17 Ibid.

18 Kementerian Energi dan Sumber Daya Mineral, "Impor Bensin RON 88 Direkomendasikan Dihentikan", $\quad$ https://migas.esdm.go.id/post/read/Impor-Bensin-RON-88--DirekomendasikanDihentikan, diakses pada 30 Mei 2018.

19 Abdul Aziz, “Inkonsistensi Pemerintah Soal Kebijakan BBM Premium” https://tirto.id/inkon sistensi-pemerintah-soal-kebijakan-bbm-premium-cKAF, diakses pada 4 September 2018. 
penyaluran bahan bakar minyak dimulai terhitung Maret 2019 beroktan 88, termasuk Premium, di Jawa dan Bali. ${ }^{20}$ Perpres ini dinilai sebagai langkah awal pemerintah untuk menghapus bahan bakar tak ramah lingkungan secara bertahap. Pada tahun 2017, standar emisi gas buang Euro 4 secara resmi diberlakukan di Indonesia melalui Permen LH dan Kehutanan No. P.20/MENLHK/SETJEN/KUM.1/3/20 17. Adapun masa transisi yang diberikan oleh Kementerian Lingkungan Hidup dan Kehutanan (KLHK) terkait penerapan standar emisi Euro 4 adalah paling lambat 1 tahun 6 bulan untuk kendaraan bermotor berbahan bakar bensin, CNG dan $\mathrm{LPG}^{21}$ serta 4 tahun untuk kendaraan bermotor berbahan bakar diesel.22 Setelah mengalami pengunduran oleh KLHK selama 6 (enam) bulan, penghitungan masa transisi penerapan Euro 4 ini akan mendatang. ${ }^{23}$

Sayangnya, konsistensi pemerintah dalam menjalankan rekomendasirekomendasi yang diberikan oleh Tim Reformasi Tata Kelola Minyak dan Gas Bumi ini tidak berlangsung lama. Pada Juli 2017, pada saat negara-negara lain berencana menerapkan kebijakan mengurangi emisi gas buang dengan melarang penggunaan kendaraan bermotor berbahan bakar minyak, ${ }^{24}$ Pemerintah Indonesia sebaliknya mengumumkan bahwa Indonesia akan kembali mewajibkan pendistribusian bahan bakar minyak beroktan rendah seperti Premium di seluruh wilayah Indonesia. Kebijakan mewajibkan kembali pendistribusian Premium ini kemudian tercantum dalam Perpres No. 43 Tahun 2018 yang disahkan oleh Presiden Jokowi pada 24 Mei 2018 lalu.

\footnotetext{
${ }^{20}$ Indonesia, Peraturan Presiden tentang Penyediaan, Pendistribusian, dan Harga Jual Eceran Bahan Bakar Minyak, Perpres No. 191 Tahun 2014, Ps. 3 ayat (3).

${ }^{21}$ Indonesia, Menteri Lingkungan Hidup dan Kehutanan. Op, cit., Ps 8 ayat (1) huruf a.

22 Ibid., Ps 8 ayat (1) huruf b.

23 Safyra Primadhyta, "KLHK Undur Masa Transisi Penerapan Standar Emisi Euro 4" https:// www.cnnindonesia.com/ekonomi/20180417094301-85-291322/klhk-undur-masa-transisipenerapan-standar-emisi-euro-4, diakses pada 30 Agustus 2018.

24 Alanna Petroff, "These countries want to ban gas and diesel cars", http://money.cnn.com/2017/09/11/ autos/countries-banning-diesel-gas-cars/index.html, diakses pada 29 Juni 2018.
} 
Pemberlakuan Peraturan Presiden ini mengakibatkan masyarakat mempertanyakan kembali komitmen Pemerintah Indonesia dalam mengontrol emisi gas buang kendaraan bermotor guna mengurangi polusi udara di Indonesia.

Prinsip pengambilan kebijakan yang harus didasari oleh bukti ini disebut juga sebagai prinsip evidence-based policy making. Dalam pengimplementasian evidence-based policy making, pemerintah dituntut untuk memiliki kemampuan untuk mengelola kebijakan hingga manfaatnya dirasakan oleh orang banyak. ${ }^{25}$ Dengan ditetapkannya Perpres ini muncul satu pertanyaan yakni: sudahkah prinsip evidence-based policy making diimplementasikan dengan baik dalam proses perumusan Perpres No. 43 Tahun 2018?
II. Komitmen Indonesia dalam Mengurangi Energi Tak Ramah Lingkungan

\section{A. Komitmen Berdasarkan Peraturan}

\section{Presiden Nomor 191 Tahun 2014}

Perpres No. 191 Tahun 2014 yang diundangkan pada tanggal 31 Desember 2014 memuat beberapa ketentuan yang berkaitan dengan komitmen Indonesia dalam mengurangi energi yang tak ramah lingkungan. Pasal 3 mengatur bahwa pemerintah melalui Perpres tersebut, membatasi pendistribusian Jenis BBM Khusus Penugasan atau BBM jenis Bensin RON minimum 88 (Premium) untuk wilayah Jawa dan Bali. Pembatasan pendistribusian didasari atas alasan tingginya konsumsi Premium pada wilayah Jawa dan Bali. ${ }^{26}$ Konsumsi Premium yang tinggi tersebut turut berkontribusi dalam kualitas udara bersih di wilayah Jawa dan Bali.

Menurut data yang dirilis oleh Greenpeace Indonesia, Jakarta dan Denpasar menempati posisi 5 (lima)

25 Sudi Fahmi, "Asas Tanggung Jawab Negara Sebagai Dasar Pelaksanaan Perlindungan dan Pengelolaan Lingkungan Hidup," Jurnal Hukum, 2, 18 (2011), hlm. 217.

26 EVY/OIN, "Kuota Premium Jawa-Bali Dibatasi", https://nasional.kompas.com/read/2010/09/22/09102483/kuota.premium.jawa-bali.dibatasi, diakses pada 4 Oktober 2018. 
besar sebagai kota dengan kualitas udara terburuk di dunia. ${ }^{27}$ Karenanya, pembatasan pendistribusian Premium di wilayah Jawa dan Bali tersebut juga merupakan sebuah bentuk kesadaran Pemerintah akan besarnya permasalahan lingkungan yang ditimbulkan oleh gas buang sisa pembakaran BBM yang mengandung bahan-bahan pencemar seperti $\mathrm{CO}_{2}$ (Carbon Dioksida), $\mathrm{NO}_{x}$ (Nitrogen Oksida), CO (Carbon Monoksida), VHC (Volatile Hydro Carbon) dan partikel lainnya. Bahan-bahan tersebut berpotensi memicu dampak negatif terhadap manusia maupun ekosistem bila melebihi konsentrasi tertentu. ${ }^{28}$

Kebijakan mengenai pembatasan pendistribusian Premium untuk wilayah Jawa dan Bali tersebut sejalan dengan beberapa peraturan yang berkaitan dengan pengendalian pencemaran udara dan permasalahan lingkungan lainnya. Peraturan perundangan tersebut antara lain; Undang-Undang Nomor 32 Tahun 2009 tentang Perlindungan dan Pengelolaan Lingkungan Hidup, Peraturan Pemerintah Nomor 41 Tahun 1999 tentang Pengendalian Pencemaran Udara, serta Permen LH tentang Baku Mutu Emisi Gas Buang Kendaraan Bermotor. Peraturan-peraturan tersebut membebankan tanggung jawab kepada Pemerintah untuk mengatur semua usaha atau kegiatan agar tidak mencemari lingkungan, khususnya dalam kegiatan transportasi dimana pemerintah diwajibkan untuk menggunakan BBM yang ramah lingkungan.

B. Komitmen secara Internasional mengenai Pengendalian dan Pengurangan Energi Tak Ramah Lingkungan

Perubahan iklim merupakan salah satu permasalahan lingkungan yang menjadi perhatian utama dari banyak

27 KumparanSAINS, "Jakarta dan Denpasar Masuk Daftar Kota Berpolusi Udara Terburuk Dunia”, 27 Juli 2018, https://kumparan.com/@kumparansains/jakarta-dan-denpasar-

masuk-daftar-kota-berpolusi-udara-terburuk-dunia-27431110790555072, diakses pada 4 Oktober 2018.

28 Sugiarti, "Gas Pencemar Udara Dan Pengaruhnya Bagi Kesehatan Manusia," Jurnal Chemica, Vol. 10, (2009), hlm. 50. 
negara di dunia. Salah satu penyebab utama dari perubahan iklim tersebut adalah meningkatnya emisi gas rumah kaca yang memicu suhu global rata-rata di permukaan bumi meningkat. Peningkatan suhu permukaan bumi tersebut diperkirakan akan menyebabkan naiknya permukaan laut dan bergesernya zona iklim. Kesadaran luas bahwa risiko kerugian ekonomi dan lingkungan yang timbul akibat perubahan iklim akan sangat tinggi, mendorong masyarakat internasional melakukan tindakan untuk mengendalikan potensi perubahan iklim. Berbagai macam tindakan, seperti negosiasi antara negara-negara terus dilaksanakan. Negosiasi yang dilaksanakan oleh negara-negara tersebut bertujuan untuk membentuk sebuah "world-wide agreement". ${ }^{29}$

"World-wide agreement" atau perjanjian internasional ini berkaitan dengan pengendalian dan pengurangan energi tak ramah lingkungan, khususnya yang berkaitan dengan permasalahan Emisi Gas Buang Kendaraan. Meskipun terdapat beberapa permasalahan mengenai pengendalian dan pengurangan energi tak ramah lingkungan masih belum dapat dipecahkan, namun negosiasi antar negara tersebut akhirnya mampu untuk merumuskan sebuah perjanjian internasional. Perjanjian internasional tersebut yaitu United Nations Framework Convention on Climate Change (selanjutnya disingkat UNFCCC).

UNFCCC merupakan sebuah konvensi internasional yang memiliki tujuan untuk mencapai "stabilization of greenhouse gas concentrations in the atmosphere at a level that would prevent dangerous anthropogenic interference with the climate system" ${ }^{30}$. Selain itu UNFCCC juga berisi komitmen dari negara-negara untuk menerapkan langkah-langkah penting dalam hal pengurangan kegiatan yang menghasilkan emisi dan mampu mencemari lingkungan udara.

29 Carlo Carraro, International Environmental Agreements on Climate Change, (Dordrecht: Kluwer Academic Publishers, 1999), hlm. 1.

30 Perserikatan Bangsa-Bangsa, United Nations Framework Convention on Climate Change, (resolution/adopted by the General Assembly, 20 Januari 1994, A/RES/48/189), Ps 2. 
Selain UNFCCC, terdapat sebuah perjanjian internasional yang juga memiliki tujuan untuk mengendalikan, mengurangi atau mencegah emisi gas rumah kaca, yaitu Kyoto Protocol to the United Nations Framework Convention on Climate Change (selanjutnya disingkat Protokol Kyoto). Protokol Kyoto memiliki hubungan yang erat dengan UNFCCC karena Protokol tersebut dibentuk dan diadopsi pada konferensi ketiga dari negara anggota UNFCCC atau the Third session of the Conference of Parties (COP3) yang diadakan di Kyoto, Jepang pada tahun 1997. Indonesia telah meratifikasi Protokol Kyoto dengan Undang-Undang 17 Tahun 2004 tentang Pengesahan Kyoto Protocol to the United Nations Framework Convention on Climate Change pada tanggal 28 Juli 2004. ${ }^{31}$

Sama halnya dengan UNFCCC, Protokol Kyoto juga berisi komitmenkomitmen dari negara-negara anggota dalam mencapai tujuan untuk membatasi atau mengurangi emisi gas rumah kaca, dengan cara menerapkan dan/atau merinci kebijakan dan tindakan lebih lanjut untuk membatasi dan mengurangi emisi gas rumah kaca. ${ }^{32}$ Selain itu, Protokol Kyoto secara umum dipandang sebagai langkah pertama yang penting menuju rezim pengurangan emisi global yang benarbenar diharapkan akan mampu menstabilkan konsentrasi gas rumah kaca. $^{33}$

Namun demikian, pada masa ini Protokol Kyoto dianggap kurang adil dan kurang efektif dalam mengikat negara-negara anggota untuk ikut terlibat dalam mengatasi perubahan iklim yang semakin parah. Ketidakadilan dan ketidakefektifan tersebut dikarenakan Protokol Kyoto hanya membebankan kewajiban kepada negara-negara maju untuk membatasi atau mengurangi emisi gas rumah kaca serta menciptakan kestabilan iklim

31 Marsudi Triatmodjo, "Implikasi Berlakunya Protokol Kyoto-1997 Terhadap Indonesia", Jurnal Hukum Internasional, Vol. 2, (2005), hlm. 302.

32 Ludivine Tamiotti, Trade and Climate Change: A Report by the United Nations Environment Programme and the World Trade Organization, (UNEP: Earthprint, 2009), hlm. 71-72.

33 Ashwani Kumar, et.al, Biofuels: Greenhouse Gas Mitigation and Global Warming: Next Generation Biofuels and Role of Biotechnology, (India: Spinger, 2018), hlm. 6. 
(Annex I Protokol Kyoto), namun kebijakan yang digunakan untuk cenderung membebaskan negara-negara menunjang penurunan emisi gas rumah berkembang dari kewajiban tersebut. kaca di Indonesia adalah penggunaan Kebijakan tersebut menyebabkan bahan bakar yang lebih bersih (fuel kewajiban negara-negara dalam switching). ${ }^{36}$

Seiring berjalannya waktu, rumah kaca tidak merata sehingga ketidakefektifan Protokol Kyoto tersebut mengakibatkan sulit tercapainya berujung pada pelaksanaan Konferensi kestabilan iklim global di bumi. ${ }^{34}$ Antar Negara Anggota (Conference of the Meskipun Indonesia bukan Parties/COP21) dari UNFCCC ke-21 yang merupakan negara anggota Annex 1 dari diadakan di Paris pada tanggal 12 Protokol Kyoto, Pemerintah Indonesia Desember 2015. Dalam COP21 tersebut, kemudian mengesahkan Perpres Nomor 196 negara-negara anggota dari 61 Tahun 2011 tentang Rencana Aksi UNFCCC mengadopsi Paris Agreement Nasional Penurunan Emisi Gas Rumah (Perjanjian Paris). Perjanjian Paris Kaca. Perpres ini disusun untuk merupakan sebuah kerangka kerja baru menindaklanjuti kesepakatan COP13, COP15, COP16 dan memenuhi komitmen Pemerintah Indonesia dalam pertemuan G-20 di Pittsburg untuk menurunkan emisi gas rumah kaca. ${ }^{35}$ Dalam bidang energi dan transportasi, Perpres ini mengatur bahwa salah satu yang mengikat secara hukum sebagai upaya yang dikoordinasikan secara internasional untuk mengatasi perubahan iklim. ${ }^{37}$ Tujuan utama dari Perjanjian Paris, sebagaimana diatur dalam Pasal 2, adalah untuk menahan kenaikan suhu rata-rata global di bawah

${ }^{34}$ Christoph Böhringer, The Kyoto Protocol: A Review and Perspectives, Discussion Paper No. 03-61, ZEWl-Zentrum für Europäische Wirtschaftsforschung/Center for European Economic Research (2003), hlm. 11.

${ }^{35}$ Indonesia, Peraturan Presiden tentang Rencana Aksi Nasional Penurunan Emisi Gas Rumah Kaca, Perpres No. 61 Tahun 2011, bagian Menimbang huruf b.

36 ibid, Lampiran I, hlm. 10.

37 Climate Focus, "The Paris Agreement Summary", Climate Focus Client Brief on the Paris Agreement III, Briefing Note, (2015), hlm. 1. 
$2^{\circ} \mathrm{C}$ (dua derajat Celcius) di atas tingkat di masa pra-industrialisasi dan melanjutkan upaya untuk menekan kenaikan suhu ke $1,5^{\circ} \mathrm{C}$ (satu setengah derajat Celcius) di atas tingkat praindustrialisasi.

Indonesia menandatangani Perjanjian Paris pada 22 April 2016, dan dilanjutkan dengan ratifikasi melalui Undang-Undang Nomor 16 Tahun 2016. Berdasarkan Perjanjian Paris, Indonesia telah berkomitmen untuk menurunkan emisi gas rumah kaca (mitigasi) pada tahun 2030 sebesar 29\% dengan kemampuan sendiri dan sampai dengan $41 \%$ bila dengan dukungan internasional. ${ }^{38}$

\section{Evidence-Based Policy Making dalam Perumusan Peraturan Presiden Nomor 43 Tahun 2018}

Gagasan evidence-based policy making merupakan sebuah gagasan yang menitik beratkan pada perumusan kebijakan lingkungan yang hanya dapat diadopsi ketika didasari ada bukti ilmiah yang meyakinkan. ${ }^{39}$ Evidence-based policy making hadir sebagai sebuah bentuk pencegahan kerusakan lingkungan yang mungkin timbul ${ }^{40}$ sebagai akibat kegagalan suatu kebijakan yang diambil oleh pembuat kebijakan. ${ }^{41}$

Peran kajian bukti ilmiah dalam pengembangan dan implementasi kebijakan terlihat dari berbagai cara antara lain: pertama, kajian bukti ilmiah berperan sebagai sumber informasi mengenai efektivitas masing-masing opsi kebijakan yang akan diambil sehingga mempermudah pengambil kebijakan dalam mengambil keputusan tentang kebijakan mana yang harus diambil. Kedua, kajian bukti ilmiah dari evaluasi kebijakan berperan sebagai sumber informasi bagi pengambil kebijakan untuk memutuskan apakah

${ }^{38}$ Nur Masripatin, et.al., Strategi Implementasi NDC (Nationally Determined Contribution), (Jakarta: Dirjen Pengendalian Perubahan Iklim KLHK RI, 2017), hlm. 2-4.

39 I Plewis, Educational Inequalities and Education Action Zones, dalam C. Pantazis dan D. Gordon (eds), Tackling Inequalities: Where Are We Now and What Can Be Done, (Bristol: Policy Press, 2000), hlm. 96.

40 Philippe, Op.cit., hlm. 6.

${ }^{41}$ Suzuette S. Soomai, "The Use and Influence of Scientific Information in Environmental Policy Making: Lessons Learned from Nova Scotia", Proceedings of the Nova Scotian Institute of Science Vol.47 Part.1, (2012), hlm. 158. 
kebijakan tersebut dapat dilanjutkan atau diperlukannya penyesuaian kebijakan demi efektivitas kebijakan itu sendiri. 42

Pada dasarnya, proses pengambilan kebijakan lingkungan memiliki ciri interdisipliner, yang tercermin dalam proses pembuatannya yaitu ketika para ahli hukum, peneliti, dan para ilmuwan berintegrasi untuk memformulasikan suatu kebijakan lingkungan. ${ }^{33}$ Oleh karena itu, bukti kajian ilmiah yang dibutuhkan untuk mendukung kebijakan harus juga bersifat interdisipliner, luas, dan jangka panjang. ${ }^{44}$ Selain itu, bukti kajian ilmiah tersebut harus dikumpulkan secara cermat dan sistematis ${ }^{45}$ serta relevan, representatif dan valid. ${ }^{46}$
Berdasarkan muatannya, terdapat 4 (empat) jenis bukti kajian ilmiah yang memiliki dampak pada proses pengambilan kebijakan, antara lain:47 data deskriptif (biaya hidup, penerimaan pajak, tingkat pasar saham, tingkat pengangguran, tingkat kesejahteraan masyarakat, dampak kesehatan), temuan analitik (penelitian yang mengidentifikasi faktor-faktor yang menyebabkan suatu hal), bukti evaluatif (mengkaji efektivitas kebijakan yang ada), dan analisis prediktif kebijakan (menghitung keuntungan dan kerugian, kemungkinan biaya dan manfaat, serta hasil yang diharapkan dari masingmasing alternatif kebijakan).

Dalam kehidupan nyata, bukti dapat muncul dari berbagai elemen

42 Ian Sanderson, "Evaluation, Policy Learning and Evidence-Based Policy Making", Public Administration, Vol.80, No.1, (2002), hlm. 4.

${ }^{43}$ C. Brodhag dan S. Taliere, "Sustainable Development Strategies: Tools for Policy Coherence", Natural Resources Forum Vol.30 No.2, (2006): hlm.136-145.; lihat juga B.W. Head, "Three Lenses of Evidence-Based Policy", Australian Journal of Public Administration Vol.67 No.1, (2008), hlm. 1-11.

${ }^{44}$ Louise Shaxson, et.al., "Developing an Evidence-based Approach to Environmental Policy Making: Insights from Defra's Evidence \& Innovation Strategy", Science \& Technology Policy Research Electronic Working Paper, No. 181, (2009), hlm. 2.

${ }^{45}$ Court, et.al. Policy Engagement: How Civil Society Can be More Effective, (London: Overseas Development Institute, 2006), hlm. 5.

46 Palmira Permata Bachtiar, "Producing Evidence to Inform Policy Process in Indonesia: The Challenges on the Supply Side", dalam The SMERU Research Institute, "Towards Pro-poor Policy Through Research", Newsletter No.32, (2011), hlm. 4.

${ }^{47}$ Carol Hirschon Weiss, "What Kind of Evidence in Evidence Based Policy?" disampaikan dalam Harvard University, 3rd International Interdisciplinary Evidence-Based Policies and Indicator Systems Conference, 2001, hlm. 288-289. 
masyarakat seperti institusi akademik, badan-badan pemerintahan dan lembaga swadaya masyarakat ${ }^{48}$ serta hadir dalam berbagai bentuk. Sebagai contoh, Pemerintah Inggris mendefinisikan bukti sebagai pengetahuan pakar, hasil penelitian yang dipublikasikan, data statistik, hasil konsultasi dengan pemangku kepentingan (stakeholders), dokumen evaluasi kebijakan sebelumnya, internet, hasil konsultasi, dokumen hitungan biaya opsi-opsi kebijakan, dan keluaran dari pemodelan ekonomi dan statistik. 49

Beralih ke dalam implementasi evidence-based policy making pada perumusan Perpres No. 43 Tahun 2018 yang berisi mengenai perubahan peraturan mengenai penyediaan, pendistribusian dan harga jual eceran bahan bakar minyak di Indonesia. Pada 24 Mei 2018, Kementerian Energi dan Sumber Daya Mineral (ESDM) mengumumkan bahwa Presiden Jokowi telah resmi menandatangani Perpres No. 43 Tahun 2018 tentang Perubahan Atas Perpres No. 191 Tahun 2014 tentang Penyediaan, Pendistribusian dan Harga Jual Eceran Bahan Bakar Minyak. ${ }^{50}$ Melalui Perpres No. 43 Tahun 2018 ini, Pemerintah menetapkan kembali Jawa dan Bali sebagai wilayah penugasan penyediaan dan pendistribusian premium.

Sejak pertama kali diberlakukan, Perpres No. 43 Tahun 2018 ini telah menuai banyak kritik dari masyarakat. ${ }^{51}$ Pertanyaan yang kemudian muncul adalah: sudahkah pemerintah mengimplementasikan prinsip evidencebased policy making dalam perumusan Perpres No. 43 Tahun 2018?

Salah satu cara untuk menelusuri implementasi evidence-based policy making dalam proses perumusan suatu peraturan perundang-undangan di Indonesia adalah dengan mempelajari naskah akademik yang mendasari

48 Suzuette, op.cit., hlm. 156.

49 UK Cabinet Office, Modernising Government White Paper, (London: Centre for Management and Policy Studies, 1999), hlm. 33.

50 TW, "Presiden Jokowi Teken Perpres Nomor 43 Tahun 2018, Premium Wajib Tersedia di Jamali", https://migas.esdm.go.id/post/read/presiden-_ jokowi-teken-perpres-nomor-43-tahun-2018pertamina-wajib-distribusikan-premium-di-jamali, diakses pada 1 Juni 2018.

${ }^{51}$ Abdul Aziz, Op.cit. 
peraturan perundangan-undangan tersebut. Sayangnya, UU No. 12 Tahun 2011 tentang Pembentukan Peraturan Perundang-undangan mewajibkan pembuatan naskah akademik hanya untuk Rancangan Undang-Undang, Rancangan Peraturan Daerah Provinsi, dan Rancangan Peraturan Daerah Kabupaten/Kota. ${ }^{52}$ Sehingga dalam proses perumusan jenis peraturan perundang-undangan lainnya, seperti Peraturan Presiden, naskah akademik tidak menjadi dokumen prasyarat.

Ketika ditelusuri melalui situs Jaringan Dokumentasi dan Informasi Hukum Nasional

(JDIHN/www.jdihn.bphn.go.id), dokumen kajian dan analisis yang mendasari pembentukan Perpres No. 43 Tahun 2018 juga tidak dapat ditemukan. Penulis hanya dapat menelusuri alasan yang mendasari pemberlakuan Perpres
No. 43 Tahun 2018 dari pernyataanpernyataan yang dikemukakan oleh Kementerian ESDM.

Dirjen Migas Kementerian ESDM, Djoko Siswanto menjelaskan bahwa pemberlakuan Perpres No. 43 Tahun 2018 adalah upaya Pemerintah untuk menjaga harga BBM dan daya beli masyarakat di tengah meningkatnya harga minyak mentah dunia. ${ }^{53}$ Selain itu, Pemerintah juga menyatakan bahwa Perpres No. 43 Tahun 2018 diberlakukan untuk menanggulangi kelangkaan premium di sejumlah daerah di Indonesia ${ }^{54}$ dan sebagai upaya preventif terjadinya inflasi. .55

Jika melihat data dari Badan Pusat Statistik (BPS), pada Juli 2018 memang

52 Indonesia, Undang-Undang Pembentukan Peraturan Perundang-Undangan, UU No. 12 Tahun 2011, LN No. 82 tahun 2011, TLN No. 5234, Ps 1 Angka 11.

53 Shintaloka Pradita Sicca, "Pemerintah Ungkap Alasan Pertamina Harus Jual Premium di Jamali", https://tirto.id/pemerintah-ungkap-alasan-pertamina-harus-jual-premium-di-jamali-cHzF, diakses pada 30 Agustus 2018.

54 Lani Diana Wijaya, "Presiden Jokowi Resmi Teken Revisi Perpres 191/2014 Soal Premium", https://bisnis .tempo.co/read/1092758/presiden-jokowi-resmi-teken-revisi-perpres-1912014-soalpremium, diakses pada 26 Mei 2018.

55 Sekretariat Kabinet RI, "Perpres dan Permen Direvisi, Archandra: Presiden Instruksikan Jamin Pasokan dan Harga Premium", https://setkab.go.id/perpres-dan-permen-di revisi-archandrapresiden-instruksikan-jamin-pasokan-dan-harga-premium/, diakses pada 31 Agustus 2018. 
terjadi inflasi sebesar 0,28 persen ${ }^{56}$ dengan kenaikan harga bensin dan tarif pulsa ponsel sebagai dua komoditas yang dominan memberikan andil/sumbangan inflasi dalam kategori transpor, komunikasi dan jasa keuangan. 57 Namun, apakah dengan hanya mempertimbangkan dampak ekonomi jangka pendek saja cukup?

Selain mengkaji dampak ekonomi jangka pendek, Pemerintah juga harus mempertimbangkan dampak ekonomi jangka panjang, ${ }^{58}$ dampak lingkungan dan dampak sosial sebelum menerbitkan suatu kebijakan. ${ }^{59}$ Dari segi dampak lingkungan, sebuah studi menunjukkan bahwa penggunaan bahan bakar beroktan tinggi akan berdampak pada pengurangan produksi emisi karbon dioksida kendaraan bermotor. ${ }^{60}$ Emisi karbon dioksida sendiri dapat menyebabkan pemanasan global, kenaikan air laut, cuaca ekstrim, meningkatnya angka kematian dan penyakit seperti asma dan kanker. ${ }^{61}$

Dampak negatif terhadap kesehatan masyarakat tersebut juga memiliki dampak sosial baik bagi orang dewasa maupun anak-anak. Sebuah studi menunjukkan bahwa polusi udara dapat menyebabkan gangguan kognitif ringan pada orang dewasa ${ }^{62}$ dan menghambat perkembangan kognitif pada anakanak. 63 UNICEF melaporkan bahwa hubungan kausalitas antara polusi udara dan timbulnya berbagai penyakit pada anak pada akhirnya menyebabkan

56 BPS, “Inflasi sebesar 0,28 persen pada Juli 2018. Inflasi tertinggi terjadi di Sorong sebesar 1,47 persen.", https://www.bps.go.id/pressrelease/2018/08/01/1435/inflasi-sebesar-0-28-persen-padajuli-2018--inflasi-tertinggi-terjadi-di-sorong-sebesar-1-47-persen-.html, diakses pada 31 Agustus 2018.

57 BPS, “Perkembangan Indeks Harga Konsumen/Inflasi," No.59/08/Th.XXI, 2018, hlm. 4.

58 UK Strategic Policy Making Team Cabinet Office, Professional Policy Making for the Twenty First Century, (London: UK Cabinet Office, 1999), Chapter. 4.1.

59 Philip Davies, "The State of Evidence-Based Policy Evaluation and Its Role in Policy Formation," National Institute Economic Review Vol.219, No.1, (2012), hlm. R.48.

60 Romany, Op.cit., hlm. 9.

61 Mark Z. Jacobson, "On the Causal Link Between Carbon Dioxide and Air Pollution Mortality", Geophysical Research Letters, Vol.35, (2008), hlm. 2-5.

62 Nicholas Rees, Clear the Air for Children, the Impact of Air Pollution on Children, (US: UNICEF, 2016), hlm. 30 .

63 Jordi Sunyer, et.al., "Association between Traffic-Related Air Pollution in Schools and Cognitive Development in Primary School Children: A prospective cohort study", PLOS Medicine 12 (3), (2005), hlm. 19. 
rendahnya tingkat kehadiran ${ }^{64}$ dan prestasi akademik anak di sekolah. ${ }^{65}$

Selain lebih ramah lingkungan, penggunaan bahan bakar beroktan tinggi ternyata juga lebih baik dari segi dampak ekonomi jangka panjang. Dalam perumusan Perpres No. 43 Tahun 2018, Pemerintah Indonesia tidak mempertimbangkan dampak ekonomi jangka panjang seperti penghematan penggunaan bahan bakar.66 Biaya terkait perancangan dan produksi mesin yang dapat digunakan untuk bahan bakar beroktan tinggi pun relatif lebih kecil jika dibandingkan dengan penghematan biaya bahan bakar selama masa pakai kendaraan. ${ }^{67}$ Selain itu, penggunaan bahan bakar beroktan tinggi juga diperkirakan akan secara langsung menghemat 7,9-14,1 miliar dollar Amerika Serikat per tahun ${ }^{68}$ atau setara dengan 117-209 triliun rupiah per tahun.
Penjelasan di atas menunjukkan bahwa pemberlakuan Perpres No. 43 Tahun 2018 ini tidak memperhitungkan dampak jangka panjang baik dari segi lingkungan, sosial maupun ekonomi. Hal ini terlihat dari tindakan Pemerintah yang mengesampingkan pemberlakuan standarisasi Euro 4 bagi kendaraan bermotor di Indonesia dengan kembali mewajibkan pendistribusian premium di seluruh wilayah Indonesia.

Sudah saatnya bagi pemerintah Indonesia untuk kembali menjalankan komitmennya dalam mengurangi penggunaan energi tak ramah lingkungan di Indonesia. Komitmen ini hanya akan terealisasi jika pemerintah Indonesia mulai mengimplementasikan prinsip evidence-based policy making dalam proses perumusan kebijakankebijakannya, guna mengetahui bentuk kebijakan terbaik yang berwawasan lingkungan.

\footnotetext{
64 Jianghong Liu dan Gary Lewis, "Environmental Toxicity and Poor Cognitive Outcomes in Children and Adults", Journal of Environmental Health, 76, 6 (2014), hlm.130-138.

65 Mohai Paul, et.al., "Air Pollution around Schools Is Linked to Poorer Student Health and Academic Performance," Health Affairs, 30, 5 (2011), hlm. 852-862.

66 Raymond L. Speth, et.al., Economic and Environmental Benefits of Higher-Octane Gasoline, (US: American Chemical Society, 2014), hlm.6566-6567.

67 Ibid.

68 Ibid.
} 


\section{Penutup}

Gagasan evidence-based policy making adalah gagasan yang menitikberatkan pada perumusan kebijakan lingkungan, yang hanya dapat diadopsi ketika didasari ada bukti ilmiah yang meyakinkan.

Dalam

mengimplementasikan evidence-based policy making, diperlukan analisa terhadap berbagai dampak seperti dampak ekonomi, lingkungan dan sosial dari suatu kebijakan. Dalam hal pemberlakuan Perpres No. 43 Tahun 2018, pemerintah Indonesia tidak secara seksama mempertimbangkan dampak jangka panjang ekonomi, lingkungan dan sosial dari Perpres ini. Hal ini juga terlihat dari ketiadaan bukti ilmiah yang dapat diakses publik di balik pembuatan kebijakan tersebut. Kebijakan untuk kembali mewajibkan pendistribusian bahan bakar beroktan rendah seperti Premium di seluruh wilayah Indonesia ini merupakan langkah mundur dalam pemberlakuan standar Euro 4 di Indonesia.

Ke depannya, guna merealisasikan komitmen Indonesia untuk mengurangi penggunaan energi tak ramah lingkungan, penting bagi Pemerintah Indonesia untuk melakukan harmonisasi kebijakan-kebijakan lintas sektor, khususnya sektor energi dan lingkungan. Salah satu langkah untuk mewujudkan harmonisasi kebijakankebijakan lintas sektor tersebut dapat dilakukan dengan mengimplementasikan prinsip evidencebased policy making di berbagai sendi pemerintahan. Hal ini dilakukan guna terciptanya kebijakan yang tidak hanya menguntungkan dalam kacamata ekonomi jangka pendek, namun juga kebijakan yang memberi dampak positif pada lingkungan di Indonesia. 


\section{DAFTAR PUSTAKA}

\section{Peraturan Perundang-Undangan}

Perserikatan Bangsa-Bangsa, United Nations Framework Convention on Climate Change, resolution / adopted by the General Assembly, 20 January 1994, A/RES/48/189. Kyoto Protocol to the United Nations Framework Convention on Climate Change, 1997, 37 ILM 22, UN Doc. FCCC/CP/1997/7/Add.1

Indonesia. Undang-undang Perlindungan dan Pengelolaan Lingkungan Hidup, UU No. 32 Tahun 2009, LN No. 140 Tahun 2009, TLN No. 5059.

. Menteri Lingkungan Hidup dan Kehutanan, Peraturan Menteri Lingkungan Hidup dan Kehutanan tentang Baku Mutu Emisi Gas Buang Kendaraan Bermotor Tipe Baru Kategori M, Kategori N, dan Kategori O, Nomor PM 20 Tahun 2017 . Peraturan Presiden tentang Rencana Aksi Nasional Penurunan Emisi Gas Rumah Kaca. Perpres No. 61 Tahun 2011.

Peraturan Presiden tentang
Penyediaan, Pendistribusian, dan
Harga Jual Eceran Bahan Bakar

Minyak. Perpres No. 191 Tahun 2014.

\section{Buku}

Birnie, Patricia, et.al. International Law \& the Environment, 3rd ed. UK: Oxford University Press. 2009.

Carraro, Carlo. International Environmental Agreements on Climate Change, Dordrecht: Kluwer Academic Publishers. 1999.

Court, et.al. Policy Engagement: How Civil Society Can be More Effective, London: Overseas Development Institute. 2006.

Djamin, Djanius. Pengawasan dan Pelaksanaan Undang-undang Lingkungan Hidup. Jakarta: Yayasan Obor Indonesia. 2007.

Kumar, Ashwani, et.al. Biofuels: Greenhouse Gas Mitigation and Global Warming: Next Generation Biofuels and Role of Biotechnology, India: Springer. 2018.

Masripatin, Nur, et.al. Strategi Implementasi NDC (Nationally Determined Contribution). Jakarta: 
Dirjen Pengendalian Perubahan Iklim, KLHK RI. 2017.

Plewis, I. Educational Inequalities and

Education Action Zones, dalam C.

Pantazis and D. Gordon (eds). Tackling Inequalities: Where Are We

Now and What Can Be Done.

Bristol: Policy Press. 2000.

Sands, Philippe. Principles of International

Environmental Law, 2nd ed. UK:

Cambridge University Press. 2007.

Siahaan, N.H.T. Hukum Lingkungan. Jakarta: Pancuran Alam. 2009.

Speth, Raymond L. et.al. Economic and Environmental Benefits of Higher-

Octane Gasoline. US: American Chemical Society. 2014.

Tamiotti, Ludivine. Trade and Climate Change: A Report by the United Nations Environment Programme and the World Trade Organization, UNEP/Earthprint. 2009.

Weiss, Carol Hirschon. What Kind of Evidence in Evidence Based Policy? Harvard University. 3rd International Interdisciplinary Evidence-Based Policies and
Indicator Systems Conference. 2001.

\section{Jurnal}

AJ, Cohen, Brauer M, Burnett R, et. al. “Estimates and 25-year trends of the global burden of disease attributable to ambient air pollution: an analysis of data from the Global Burden of Diseases Study 2015." The Lancet Vol. 389, (2017).

Brodhag, C. dan S. Taliere. "Sustainable Development Strategies: Tools for Policy Coherence," Natural Resources Forum Vol.30 No.2. (2006).

Carvalho, Helotonio. "The Global Burden of Air PollutionAssociated Deaths - How Many Are Needed for Countries to React?" Elsevier Ltd. (2017).

Davies, Philip. “The state of evidencebased policy evaluation and its role in policy formation," National Institute Economic Review Vol.219, No.1. (2012). 
Fahmi, Sudi. “Asas Tanggung Jawab Negara Sebagai Dasar

Pelaksanaan Perlindungan dan Pengelolaan Lingkungan Hidup." Jurnal Hukum No. 2 Vol.18. (2011).

Head, B.W. “Three Lenses of EvidenceBased Policy." Australian Journal of Public Administration Vol.67 No.1. (2008).

Jacobson, Mark Z. “On the Causal Link Between Carbon Dioxide and Air Pollution Mortality," Geophysical Research Letters, Vol.35. (2008).

Liu, Jianghong dan Gary Lewis. "Environmental Toxicity and Poor Cognitive Outcomes in Children and Adults," Journal of Environmental Health, Vol.76, No.6. (2014).

Paul, Mohai, et.al. "Air Pollution around Schools Is Linked to Poorer Student Health and Academic Performance," Health Affairs, Vol.30, No.5. (2011).

Sanderson, Ian. "Evaluation, Policy Learning and Evidence-Based Policy Making," Public Administration, Vol.80, No.1. (2002).
Soomai, Suzuette S. "The Use and Influence of Scientific Information In Environmental Policy Making: Lessons Learned from Nova Scotia," Proceedings of the Nova Scotian Institute of Science Vol.47 Part.1. (2012).

Sugiarti. "Gas Pencemar Udara dan Pengaruhnya Bagi Kesehatan Manusia." Jurnal Chemica. Vol. 10. (2009).

Sunyer, Jordi, et.al. "Association between Traffic-Related Air Pollution in Schools and Cognitive Development in Primary School Children: A prospective cohort study." PLOS Medicine 12(3). (2005).

Triatmodjo, Marsudi. "Implikasi Berlakunya Protokol Kyoto-1997 Terhadap Indonesia." Jurnal Hukum Internasional, Vol. 2. (2005).

\section{Lain-Lain}

Alanna Petroff. "These Countries Want to Ban Gas and Diesel Cars." http://money.cnn.com/ 2017/09/11/autos/countriesbanning-diesel-gas- 
cars/index.html, diakses pada 29 Juni 2018.

Bachtiar, Palmira Permata. Producing Evidence to Inform Policy Process in Indonesia: The Challenges on the Supply Side, dalam The SMERU Research Institute, Towards Propoor Policy Through Research, Newsletter No. 32. 2011.

Böhringer, Christoph. The Kyoto Protocol: A Review and Perspectives, Discussion Paper No. 03-61, ZEWZentrum für Europäische Wirtschaftsforschung/Center for European Economic Research (2003).

BPS. "Inflasi sebesar 0,28 persen pada Juli 2018. Inflasi tertinggi terjadi di Sorong sebesar 1,47 persen.", https://www.bps.go.id/pressrel ease/2018/08/01/1435/inflasisebesar-0-28-persen-pada-juli2018--inflasi-tertinggi-terjadi-disor ong-sebesar-1-47-persen.html, diakses pada 31 Agustus 2018.

BPS. Perkembangan Indeks Harga Konsumen/Inflasi, No.59/08/Th.XXI, 2018.
Climate Focus, "The Paris Agreement Summary", Climate Focus Client Brief on the Paris Agreement III, Briefing Note, (2015).

EVY/OIN. "Kuota Premium Jawa-Bali Dibatasi."

https://nasional.kompas.com/re $\mathrm{ad} / 2010 / 09 / 22 / 09102483 /$ kuota. premium.jawa-bali.dibatasi. diakses pada 4 Oktober 2018.

Hermawan, Arief. "Indonesia Masih Terbelakang Soal Standar Emisi Kendaraan",

https://tirto.id/indonesia-masihterbelakang-soal-standar-emisikendaraan-cjxI. diakses pada 3 September 2018.

Hermawan. "Inkonsistensi Pemerintah Soal Kebijakan BBM Premium" https://tirto.id/inkonsistensipemerintah-soal-kebijakan-bbmpremium-cKAF. diakses pada 4 September 2018.

Kementerian ESDM. "Impor Bensin RON 88 Direkomendasikan Dihentikan."

https://migas.esdm.go.id/post/ read/Impor-Bensin-RON-88-- 
Direkomendasikan-Dihentikan, diakses pada 30 Mei 2018.

Kementerian ESDM. "Presiden Jokowi

Teken Perpres Nomor 43 Tahun 2018, Premium Wajib Tersedia di Jamali."

https://migas.esdm.go.id/post/ read/ presiden-jokowi-tekenperpres-nomor-43-tahun-2018pertamina-wajib-dis tribusikanpremium-di-jamali. diakses pada 1 Juni 2018.

KLHK RI. “Standar Emisi Euro 4 Segera Diberlakukan di Indonesia." http://ppid.menlhk.go.id/siaran _pers/browse/579, diakses pada 3 September 2018.

KLHK RI. "Asas Perlindungan dan Pengelolaan Lingkungan Hidup." http://www.menlh.go.id/asasperlindungan-dan-pengelolaanlingkungan-hidup/d diakses pada 30 Mei 2018.

Kumparan SAINS. "Jakarta dan Denpasar Masuk Daftar Kota Berpolusi Udara Terburuk Dunia", 27 Juli 2018, https://kumparan.com/@kumpa ransains/jakarta-dan-denpasar$\underline{\text { masuk-daftar-kota-berpolusi- }}$ udara-terburuk-dunia27431110790555072. diakses pada 4 Oktober 2018.

Lani Diana Wijaya. "Presiden Jokowi Resmi Teken Revisi Perpres 191/2014 Soal Premium." https://bisnis.tempo.co/read/10 92758/presiden-jokowi-resmiteken-revisi-perpres-1912014soal-premium, diakses pada 26 Mei 2018.

Rees, Nicholas. Clear the Air for Children, the Impact of Air Pollution on Children. US: UNICEF. 2016.

Sekretariat Kabinet RI. "Perpres dan Permen Direvisi, Archandra: Presiden Instruksikan Jamin Pasokan dan Harga Premium", https://setkab.go.id/perpresdan-permen-direvisi-archandrapresiden-instruksikan-jaminpasokan-dan-harga-premium/, diakses pada 31 Agustus 2018.

Shaxson, Louise. et.al. 2009. Developing an Evidence-based Approach to Environmental Policy Making: Insights from Defra's Evidence $\mathcal{E}$ Innovation Strategy. Science \& 
Technology Policy Research Electronic Working Paper.

Shaxson, Louise. Pelajaran untuk

Membangun dan Mengelola Basis Bukti untuk Kebijakan, Kementerian PPN/Bappenas

Working Paper, No. 10. 2016.

Suhartono, Anton. “Akan Diberlakukan

pada 2018, Apa Itu Standar Emisi Euro4?",

https://news.okezone.com/read L2017/04/03/15/1657747/akandiberlakukan -pada-2018-apa-itustandar-emisi-euro4, diakses pada 7 September 2018.

Surat Menteri KLHK kepada Presiden Jokowi Nomor S.108/Menlhk/Setjen/PKL.3/3/ 2018.

Tempo. “Kebijakan Energi Jokowi Tak Konsisten."

https://koran.tempo.co/read/42 9636/kebijakan-energi-jokowitak-konsisten, diakses pada 11 April 2018.

Theiss, Tim. et.al. Summary of HighOctane, Mid-Level Ethanol Blends Study 2. Oak Ridge: Oak Ridge National Laboratory. (2016).
Utama, Praga. "Ini Beda Premium, Pertalite, Pertamax, dan Pertamax Plus", https://bisnis.tempo.co/read/67 8224/ini-beda-premiumpertalite-pertamax-danpertamax-plus. diakses pada 3 September 2018.

UK Cabinet Office. Modernising Government White Paper. London: Centre for Management and Policy Studies. 1999.

UK Strategic Policy Making Team Cabinet Office. Professional Policy Making for the Twenty First Century. London: UK Cabinet Office, 1999.

Webb, Romany M. Increasing Gasoline Octane Levels to Reduce Vehicle Emissions: A Review of Federal and State Authority, New York: Sabin Center for Climate Change Law. 2001. 